Revue d'histoire de l'Amérique française

REYUE D.HISTOIRE DE L'AMÉRIQUE FRANÇAISE

\title{
Réplique à la réponse de Jacques Portes
}

\section{Jean-Pierre Charland}

Volume 49, numéro 2, automne 1995

URI : https://id.erudit.org/iderudit/305439ar

DOI : https://doi.org/10.7202/305439ar

Aller au sommaire du numéro

Éditeur(s)

Institut d'histoire de l'Amérique française

ISSN

0035-2357 (imprimé)

1492-1383 (numérique)

Découvrir la revue

Citer ce compte rendu

Charland, J.-P. (1995). Compte rendu de [Réplique à la réponse de Jacques

Portes]. Revue d'histoire de l'Amérique française, 49(2), 298-300.

https://doi.org/10.7202/305439ar d'utilisation que vous pouvez consulter en ligne.

https://apropos.erudit.org/fr/usagers/politique-dutilisation/ 


\section{Réplique de Jean-Pierre Charland}

Monsieur Portes a mal reçu un compte rendu plutôt vif, il est vrai, que je faisais de son livre. J'y trouvais de multiples erreurs affectant, selon moi, la crédibilité de l'ensemble. Monsieur Portes évoque bien ces erreurs, mais feint de ne pas comprendre ce que je soulignais. Bien plus, le fait de les avoir signalées prouverait mon ignorance. Voyons voir.

Les vétilles: dans l'index John Turner est bien appelé John, mais Jim à la page 135; Daniel Lavoie est présenté comme Franco-Ontarien (p. 148). 
Un peu plus grave, toujours sur qui a fait quoi: «Le premier [Molson] est un des financiers du Canadian Pacific Railways avant de donner naissance à une lignée de brasseurs...» (p. 24): le Dictionnaire biographique indique que John Molson (le vieux) a investi dans une brasserie en 1782, un siècle avant la fin des travaux du chemin de fer transcontinental. «En 1959, il [René Lévesque] quitte Radio-Canada à la suite d'une longue grève, puis devient ministre du gouvernement de Jean Lesage en 1966» (p. 43). Dois-je indiquer où est l'erreur?

Plus grave, car cela touche à l'interprétation: sur le rôle des clercs dans l'enseignement (p. 24), je vois avec plaisir l'admission de l'auteur qu'il y avait des femmes laïques dans l'enseignement public: de fait, elles étaient majoritaires. «Au Québec, l'Église catholique qui redoute l'urbanisation avec ses risques de tentations multiples et de promiscuité, tente d'encadrer les nouveaux citadins en maintenant dans les villes un maillage serré de paroisses qui procurent seules l'éducation et assurent l'éventuelle promotion sociale» (p. 30). Ceci est faux, car les paroisses n'assurent aucun service éducatif. Puis l'influence de l'Église est-elle si absolue? Sur la période où le Parti québécois était au pouvoir: «[La] loi 101... oblige les parents qui ne sont pas tous deux de langue anglaise, ainsi que les immigrants, à mettre leurs enfants dans les écoles françaises» (p. 144). Tout à fait faux, puisque c'est la langue de l'école fréquentée par l'un des parents au Québec, puis au Canada, qui donne accès à l'école anglaise.

À tout le moins déplacé: Portes se surprend que je lui reproche quelques expressions «politiquement incorrectes» (p. 26) quand il parle de Laurier et de Trudeau. L'élégance, le sens du compromis, les qualités d'expression ne se trouvent dans aucun héritage ethnique particulier. Il peut penser, et écrire, le contraire; j'ai le droit de trouver cela déplacé dans un manuel universitaire.

Le poids relatif des sujets et une bibliographie lacunaire: l'auteur dit avoir le droit de s'adresser à un public français et de mettre l'accent sur les sujets qui vont l'intéresser. Écrivant pour une revue montréalaise, j'ai celui d'indiquer que ces choix attireront l'intérêt des lecteurs de l'hexagone plutôt que ceux d'ici. Quant à la bibliographie, qui devrait être la liste de ses matériaux, suis-je tenu à garder sous silence l'absence d'ouvrages fondamentaux et la présence de textes qu'il n'a visiblement pas utilisés? Portes admet ne pas avoir traité de l'éducation (assez toutefois pour donner deux affirmations inexactes), alors j'ai raison de me surprendre de trouver Berthelot en bibliographie, mais pas Roby sur les investissements américains, dont il traite.

Ces erreurs sont-elles aussi bénignes qu'il le dit? L'Histoire du Québec contemporain serait-elle toujours utilisée dans les cégeps et les universités si sa lecture de la loi 101 était celle de Portes? Je n'en dresse pas une liste exhaustive: quelques-unes au début, puis à la fin du texte pour bien montrer que j'ai tout lu attentivement. Comment l'ouvrage d'un universitaire, publié chez un éditeur prestigieux, peut-il contenir des erreurs de ce genre? J'ai risqué une explication: spécialiste de la civilisation nord-américiane, Portes regarde peut-être de trop loin la réalité québécoise et canadienne pour se souvenir toujours du prénom de Turner, de l'année de l'élection qui a porté 
Lesage au pouvoir, des mécanismes par lesquels l'Église catholique a pesé sur l'école, du contenu de la loi 101. Il demande s'il faut consacrer sa vie au Québec pour écrire sur lui: non, il faut simplement le connaître assez pour éviter les erreurs grossières.

L'envolée sur le syndrome de Tocqueville comme le conflit d'intérêt où je serais témoignent bien du souci de Portes d'attirer l'attention sur moi, plutôt que sur son livre. Les historiens publient aussi de ce côté de l'Atlantique. N'avoir rien publié deviendra-t-il une exigence pour faire un compte rendu? Je concluais le mien en disant que l'ouvrage de Portes ne connaîtrait pas une grande carrière ici, même s'il rendait compte studieusement des grandes synthèses publiées sur le Québec et le Canada. Je disais même pourquoi: il y a trop de bonnes synthèses pour que les lecteurs du Québec et du Canada s'attardent sur un livre émaillé d'erreurs.

Mais il peut lui plaire d'attribuer ma critique assez vive à d'autres causes que les insuffisances de son travail. Grand bien lui fasse. 